\title{
DESEMPENHO DA COLHEDORA DE MILHO PENHA CLM-350 - PARTE III - DANOS MECÂNICOS *
}

\author{
J.A. Furlani Jr. ** \\ J.B. Guimarães $\mathrm{Jr}{ }^{* *}$ \\ L.A. Balastreire ***
}

\section{RESUMO}

$\mathrm{Cm}$ vistas a estudar o efeito do sistema de debulhamento na qualidade dos grãos de milho, realizou-se o presente trabalho, onde foram estudados os danos mecânicos sofridos pelos grãos, bem como os danos mecânicos invisíveis, evidenciados pelos testes de germinação. Nos diversos tratamentos estudados, determinou-se a porcentagem de umidade presente nos grãos de milho.

Definiu-se a velocidade periférica do debulhador, pelo diâmetro $(300 \mathrm{~mm})$ do mesmo e as rotações, para os diversos tratamentos.

$\mathrm{O}$ delineamento experimental foi de blocos ao acaso com 5 tratamentos e 6 repetições onde foram estudados os valores percentuais de grãos inteiros e quebrados, os teores de umidade correspondentes e os valores de germinação através da análise de variância. Empregou-se o teste $\mathrm{F}$ aos níveis de $1 \%$ e $5 \%$ de probabilidade c o teste Tukey para comparação entre as médias.

$\mathrm{Da}$ análise pode-se concluir que em relação ao teor de umidade dos grăos, os tratamentos não diferiram estatisticamente.

* Trabalho apresentado no V Congresso Nacional de Engenharia Agrícola de 16 a 19 de julho de 1975, em Lavras - MG. Entregue para publicação em 31-12-1977.

* Departamento de Engenharia Rural da Faculdade de Ciências Agronômicas, Campus de Botucatu - UNESP.

*** Departamento de Engenharia Rural da ESALQ-USP. 


\section{INTRODUÇÃO}

Tendo em vista ampliar o estudo referente a eficácia do sistema de debulhamento, quantificando os diversos parâmetros envolvidos, realizou-se o presente trabalho onde foram estudados as porcentagens dos grãos inteiros obtidos no sistema ensacador, as percentagens de grãos quebrados provocados, pelas diversas velocidades periféricas do debulhador. Tais parâmetros são apontados por diversos autores como danos mecânicos visíveis, que além de depreciar o produto, facilitam a ação de organismos nocivos durante o armazenamento.

Um outro parâmetro que foi estudado e que de certa forma assume importância quando se aplica a colhedora mecânica com o propósito de obtenção de sementes de milho é a porcentagem de germinação obtidas em testes de germinação. Tal avaliação serviu como indicação para futuros trabalhos, onde este parâmetro de eficácia do sistema de debulhamento pode se tornar fator limitante. Alguns autores classificam este parâmetro como dano mecânico invisível, pelo fato da ação mecânica do debulhador provocar injuria não visível mas que terá reflexos no poder germinativo das sementes. Não se constitue em dano quando se trata de colheita de grãos para alimentação.

\section{REVISÃO DA LITERATURA}

GOSS et al. (1955) estudando combinadas para colheita mecânica de milho, em velocidades de 3,2 e $1,61 \mathrm{~km} / \mathrm{h}$ obtiveram os seguintes resultados no que tange aos danos mecânicos: o milho debulhado com velocidades perifericas do cilindro batedor de $19,3 \mathrm{~m} / \mathrm{s}$ ou menos, apresentou de 3 a $4 \%$ de grãos danificados e impurezas; b) o milho debulhado com velocidades periféricas do cilindro batedor de $14,7 \mathrm{~m} / \mathrm{s}$ ou menos, apresentou 2\% ou menos de grãos danificados mecânicamente e impurezas. Concluíram que as diferenças em danos mecânicos nos grãos de milho são significativas nas relações de velocidades utilizadas no cilindro batedor acima de $15,2 \mathrm{~m} / \mathrm{s}$.

PICKARD (1955) estudou vários fatores que afetam as combinadas, quando utilizadas na colheita mecânica do milho. Concluiu que a utilização de cilindros tipos raspadores parece ser superior aos cilindros de barras anguláveis com relação aos danos mecânicos causados aos grãos. A utilização de borrachas nos cilindros batedores e concavos parece ter pouco efeito nos danos mecânicos. Quanto a umidade do grão de milho, com relação aos danos mecânicos sofridos, os dados indicaram que os teores entre 30 a $25 \%$ de umidade são críticos.

MORRISON (1955) realizou ensaios com uma combinada estacionada, alimentada por meio de calhas condutoras, que simularam con- 
dições de campo, de uma cultura com produção de $880 \mathrm{~kg} / \mathrm{ha}$ e uma velocidade da máquina de $5,63 \mathrm{~km} / \mathrm{h}$. Nas condições dos ensaios, verificou que os danos mecânicos nos grãos aumentaram rapidamente quando a velocidade angular do cilindro batedor ultrapassou $453 \mathrm{rpm}$. Por outro lado, os danos mecânicos nos grãos, geralmente foram elevados nos altos teores de umidade dos grãos. Comparou os danos mecânicos provocados pela combinada e colhedora debulhadora convencional (projetada par colheita de grãos com $15 \%$ de umidade ou menos); a combinada provocou maiores danos para valores inferiores a $15 \%$. Nos teores de 15 a $20 \%$, não houveram apreciáveis diferenças nos danos miecânicos aos grãos entre as duas máquinas. Acima de $20 \%$ no teol le umidade no grão, a combinada resultou em menores danos mecânicos em relação à colhedora convencional.

JOHNSON et al (1963) com relação à variação de teores de umidade nos grãos concluíram que quando a umidade aumentou de 21 a $35 \%$ no grãos, os danos mecânicos aumentaram de 0,5 a 3,5\%.

BYG e HALL (1968) em seus ensaios cocnluíram que as altas velocidades do cilindro batedor da combinada produziram altos índices de danos mecânicos aos grãos de milho.

WAELTY e BUCHELE (1969) estudaram os danos mecânicos aos grãos de milho provocados durante o debulhamentó, com os objetivos de determinar as propriedades físicas e morfológicos dos grãos e sabugos e correlacionar através de experimentos, as propriedades acima, com os danos mecânicos causados ao grão, como um resultado da operação de debulhamento. Concluíram que quando a umidade do grão diminui, decrescem os danos mecânicos sofridos pelos grãos. . Não foram obtidos diferenças em danos mecânicos nos grãos por debulhamento no campo e debulhamento de espigas em laboratórios. A época de plantio não afetou o dano mecânico nos grãos. Baixos índices de danos mecânicos nos grãos foram associados com pequenas forças de debulhamento, alta resistência do grão, pequena deformação do grão e baixa resistência do sabugo. O dano mecânico foi positivo com relação a umidade e é dado pela equação $\mathrm{y}=\mathrm{ax}+\mathrm{b}$, onde y é o logarítmo do dano mecânico e $x$ o logarítmo do teor de umidade, para variação da umidade de 15 a 38\%.

BRASS e MARLEY (1973) estudaram diferentes mecanismos debulhadores com vistas aos danos mecânicos provocados nos grãos. Da comparação resultou uma redução significativa nos danos mecânicas totais do grão pelo uso do rolo debulhador, quando comparado com o cilindro batedor. O dano mecânico mínimo ao grão para o cilindro batedor ocorreu aproximadamente a $19 \%$ de umidade, enquanto o dano mecânico mínimo para o rolo debulhador ocorreu a níveis de umidade mais baixos. Reduções nos danos mecânicos de aproximadamente $50 \%$ foram obtidas com o rolo debulhador quando comparado com o tipo cilindro batedor, para teores de umidade abaixo de $20 \%$ no grão. Redu- 
ções nos cianos mecânicos de aproximadamente $20 \%$ foram obtidas com teor de umidade no grão de $25 \%$. Para o debulhador tipo cilindro batedor o teor de umidade do grão, velocidade do cilindro batedor e abertura do côncavo são variáveis significantes, afetando os danos mecânicos nos grãos.

\section{MATERIAIS E MÉTODOS}

Os materiais utilizados na presente investigação compreendem os grãos de milho obtidos no sistema ensacador da colhedora Penha CLM350, pela ação dos sistemas de debulhamento e de limpeza, o tacômetro da marca JAQUET, modelo 620 todos já descritos em trabalhos anteriores ( (Partes I e II).

Foram utilizados 5 tratamentos com 6 repetições designados por $A, B, C, D$ e $E$ correspondentes às velocidades periféricas do debulhador. Definiu-se a velocidade periférica do debulhador, pelo diâmetro $300 \mathrm{~mm}$ ) e as rotações do mesmo. Em função destes valores foram quantificadas as perdas, causadas nos grãos de milho colhidos, por danos mecânicos. O delineamento experimental foi de blocos ao acaso.

O sistema de debulhamento promove a quebra dos grãos de milho, por causa das injúrias mecânicas. Todo o milho colhido e recebido no sistema ensacador, foi pesado e posteriormente por separação manual, obteve-se os valores percentuais de grãos inteiros e grãos quebrados, tomando-se o milho no sistema ensacador como $100 \%$.

GOSS et al (1955), PICKARD (1955), MORRISON (1955), BYG e HALL (1968), WAELTY e BUCHELE (1969) e BRASS E MARLEY (1973) concluíram de seus trabalhos que existem vários fatores, que concorrem para provocar danos mecânicos nos grãos de milho, no sistema debulhador, tais como: teor de umidade do grão, forma e material utilizados no sistema, folga entre o elemento móvel e a peneira, e a velocidade periférica do mecanismo móvel.

Neste trabalho, tendo em vista a concepção mecânica da máquina, sendo a distância livre entre o debulhador e o tambor de peneira, fixa e de $32,5 \mathrm{~mm}$, bem como a forma e o material constante nos diversos tratamentos, as únicas variáveis envolvidas foram a velocidade periférica do debulhador e o teor de umidade dos grãos.

Do milho recolhido no sistema ensacador, de todas as parcelas foi retirada uma amostra para a determinação do teor de umidade do grão. Essas amostras foram pesadas e colocadas em estufa até pêso constante, determinando-se o teor de umidade do grão, tomados na base umida (b.u.) isto é, o valor percentual foi explicítado em relação ao pêso total úmido da amostra e não ao pêso sêco. 
Com relação a velocidade periférica do sistema de debulhamento, procurou-se avaliar esse efeito sobre a porcentagem de germinação. Esta de certa forma caracteriza um dano invisível, apontado por diversos autores, como importante e geralmente de conseqüências futuras. Também visou-se obter, dados preliminares para futuros estudos, com respeito a colheita mecanizada de milho, a ser utilizado para semente. Uma amostra dos grãos inteiros de milho foram ensaiados quanto à germinação, para os diferntes tratamentos, em condições padronizadas

Os resultados obtidos foram estudados através da análise de variância, empreganao-se o teste $\mathrm{F}$ aos níveis de $1 \%$ e $5 \%$ de probabilidade. $\mathrm{O}$ teste Tukey aos níveis de $1 \%$ e $5 \%$ de probabilidade foi utilizado para comparação estatística entre as médias dos tratamentos. Os dados obtidos em porcentagens foram transformados em arcoseno $\vee \%$.

\section{RESULTADOS E DISCUSSÃO}

Os resultados obtidos estão assinalados no Quadro 1, e referem-se as médias de 6 repetições.

Quadro 1 - Resultados da ação mecânica do sistema de debulhamento nos grãos de milho.

\begin{tabular}{|c|c|c|c|c|c|}
\hline $\begin{array}{l}\text { Trata- } \\
\text { mento }\end{array}$ & $\begin{array}{l}\text { Velocidade } \\
\text { periférica } \\
\text { do debu- } \\
\text { lhador } \\
\mathrm{m} / \mathrm{s} \\
(2)\end{array}$ & $\begin{array}{c}\text { Teor de } \\
\text { umidade } \\
\text { (b.u.) } \\
\% \\
\text { (3) }\end{array}$ & $\begin{array}{c}\text { Grãos } \\
\text { inteiros } \\
\%\end{array}$ & $\begin{array}{c}\text { Grãos } \\
\text { quebrados } \\
\%\end{array}$ & $\begin{array}{c}\text { Teor de } \\
\text { germinação } \\
\% \\
\text { (6) }\end{array}$ \\
\hline A & 13,59 & 15,86 & 96,98 & 0,94 & 84 \\
\hline B & 15,71 & 15,98 & 94,34 & 1,90 & 84 \\
\hline C & 17,57 & 16,02 & 90,26 & 2,87 & 76 \\
\hline $\mathrm{D}$ & 20,16 & 15.22 & 82,06 & $-4,31$ & 72 \\
\hline $\mathrm{E}$ & 13,31 & 15,81 & 96,85 & 1,15 & 72 \\
\hline
\end{tabular}

Inicialmente, procedeu-se a análise de variância dos teores de umilade dos grãos, a fim de estimar-se uma possível interação nos danos necânicos. Este fator foi apontado por diversos autores em trabalhos já citados, como influenciando a injuria mecânica dos grãos.

Os dados obtidos dos teores de umidade apresentaram a seguinte análise mostrada no Quadro 2. 
Quadro 2 - Análise de variância los teores dz umidade dos gräos no sistema ensacador.

\begin{tabular}{lcccc}
\hline $\begin{array}{l}\text { Causas de } \\
\text { variação }\end{array}$ & GL & $\begin{array}{l}\text { Soma dos } \\
\text { quadrados }\end{array}$ & $\begin{array}{c}\text { Quadrados } \\
\text { médios }\end{array}$ & F \\
\hline \hline Blocos & 5 & 0,5872 & $0,117+$ & 0,4806 N.S. \\
Tratamento & 4 & 1,5419 & 0,3855 & 1,5776 N.S. \\
Resíduo & 20 & 4,8872 & 0,2444 & \\
\hline Total & 29 & 7,0163 & & \\
\hline
\end{tabular}

$\mathrm{CV}=2,11 \%$

Da análise pode-se concluir que em relação ao teor de umidade dos grãos, os tratamentos não aiferiram significativamente entre si, apresentando um teor médio de umidade de $15,78 \%$ (b.u.). Esse resultado era de certa forma esperado tendo em vista a metodologia adotada ra colheita, realizando-a num curto período de tempo.

A velocidade periférica do sistema debulhador é um valor diretamente ligado a rotação do motor, mas que também pode ser afetado por fatores não controláveis em condições de campo. Isto levou a proceder a análise de variância do Quadro 3., com a finalidade de se verificar, se os valores obtidos diferiam entre si, em função dos tratamentos estabelecidos.

Quadro 3 - Análise de variância da velocidade periférica do debulhador.

\begin{tabular}{lrrrr}
\hline $\begin{array}{l}\text { Causas de } \\
\text { variação }\end{array}$ & G L & $\begin{array}{r}\text { Soma dos } \\
\text { quadrados }\end{array}$ & $\begin{array}{c}\text { Quadrados } \\
\text { médios }\end{array}$ & F \\
\hline \hline Blocos & 5 & 0,1842 & 0,0368 & $0,511+$ N.S. \\
$\begin{array}{l}\text { Tratamento } \\
\text { Resíduo }\end{array}$ & 4 & 196,9980 & 49,2495 & 683,7074 \\
& 20 & 1,4407 & 0,0720 & \\
\hline Total & 29 & 198,6228 & & \\
\hline
\end{tabular}

$\mathrm{CV}=1,67$

Nos testes das médias foram encontradas diferenças altamente significativas. Somente entre os tratamentos A e $\mathbf{E}$ o teste não apresentou diferenças significativas, o que era de certa forma esperado, pois esses tratamentos são decorrentes da mesma rotação do motor.

Para verificar a possível influência da velocidade periférica do sistema debulhador em relação à porcentagem de grãos inteiros, valeu-se na análise de variância apresentada no Quadro 4. 
Quadro 4 - Análisc de variância refercnte às porcentagens de grãos inteiros no ensacador.

\begin{tabular}{lcccc}
\hline $\begin{array}{l}\text { Causas de } \\
\text { variação }\end{array}$ & GL & $\begin{array}{l}\text { Soma dos } \\
\text { quadrados }\end{array}$ & $\begin{array}{c}\text { Quadrados } \\
\text { médios }\end{array}$ & F \\
\hline Blocos & 5 & 310,8754 & 62,1751 & $3,1425^{*}$ \\
Tratamento & 4 & 843,5350 & 210,8838 & $10,6587^{* *}$ \\
Residuo & 20 & 395,7038 & 19,7852 & \\
\hline Total & 29 & $1.550,1143$ & & \\
\hline CV & & & &
\end{tabular}

$\mathrm{CV}=5,93 \%$

Nos testes das médias foram encontradas diferenças altamente significativas entre os traiamentos $\mathrm{A}, \mathrm{B}$ e $\mathrm{E}$ e o tratamento $\mathrm{D}$; diferença significativa entre os tratamentos D e C. Observando-se o Quadro 1 coluna (4), conclui-se que o tratamento $D$ apresentou a menor média.

Confrontando-se os valores das colunas (2) e (4) do Quadro I, podese concluir que existe uma relação inversa entre as duas variáveis nas condições do ensaio, conforme mostra a Figura 1 abaixo.

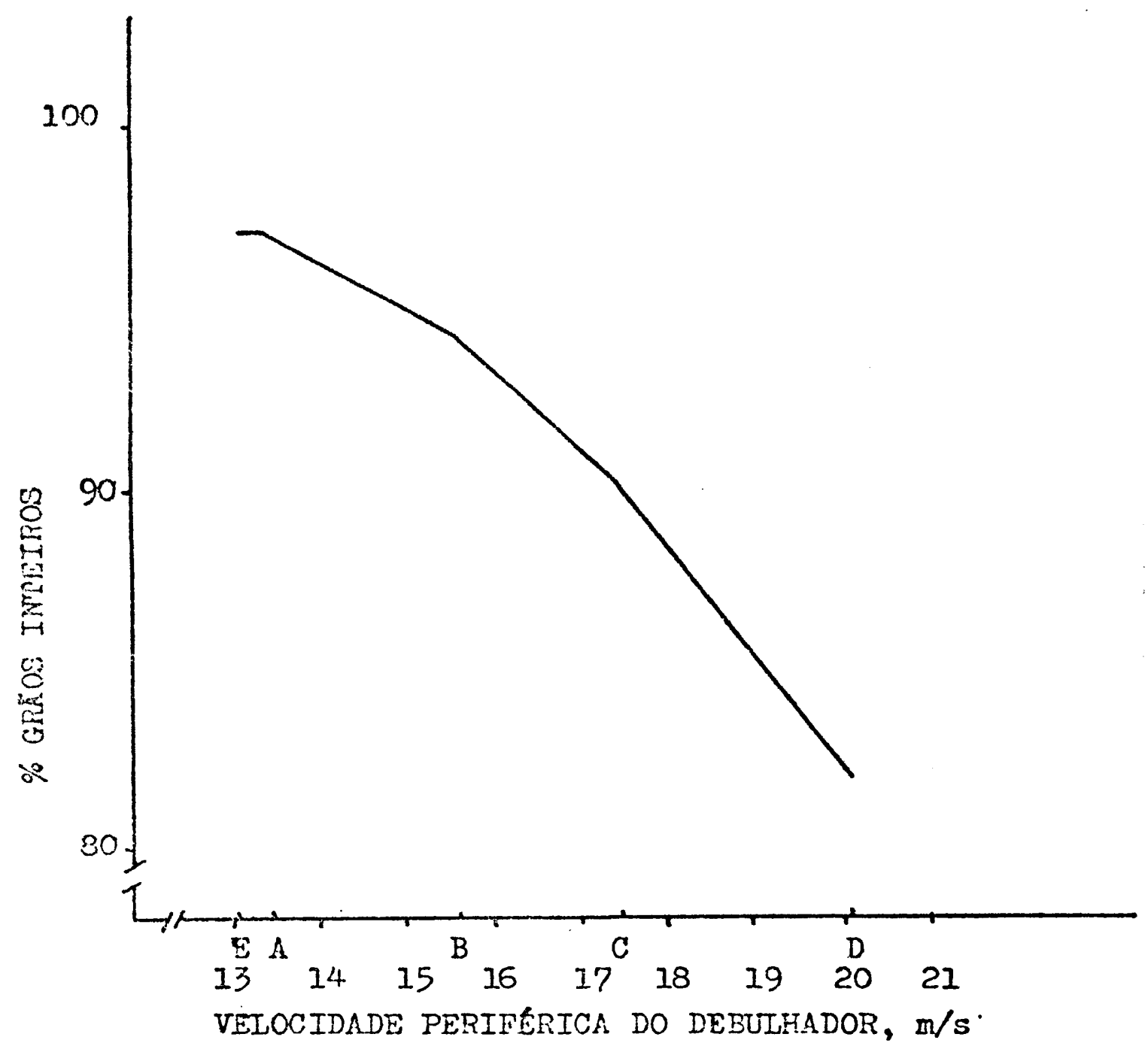

FIGURA 1 - Relação entre a velocidado periférica do debulhador e grãos inteiros 
Os dados obtidos em porcentagem de grãos quebrados apresentaram a análise de variância mostrada no Quadro 5.

Quadro 5 - Análise de variância relativa as porcentagens de grãos quebrados no ensacador.

\begin{tabular}{lcrrr}
\hline $\begin{array}{l}\text { Callsas de } \\
\text { variação }\end{array}$ & (i) & $\begin{array}{c}\text { Soma dos } \\
\text { quadrados }\end{array}$ & $\begin{array}{c}\text { Quadrados } \\
\text { médios }\end{array}$ & F \\
\hline PBlocos & 5 & 22,1586 & 4,4317 & $4,6417^{* * *}$ \\
Tratamento & 4 & 163,0626 & 40,7656 & $42,6974^{* *}$ \\
Resíduo & 20 & 19,0951 & 0,9548 & \\
\hline Total & 29 & 204,3163 & & \\
C CV $=11,87 \%$ & & & &
\end{tabular}

Nos testes das médias foram encontradas diferenças altamente significativas entre todos os tratamentos com exceção do contraste A e E. A não significância desse contraste pode ser explicada, observandose o Quadro 1, considerando-se a análise do Quadro 3, onde os tratamı 1tos A e E não diferiram.

Confrontando-se as colunas (2) e (5) do Quadro 1, conclui-se que uma relação direta existe entre a porcentagem de grãos quebrados e a velocidade periférica do debulhador. Esse relação é visualisada na Figura 2 abaixo.

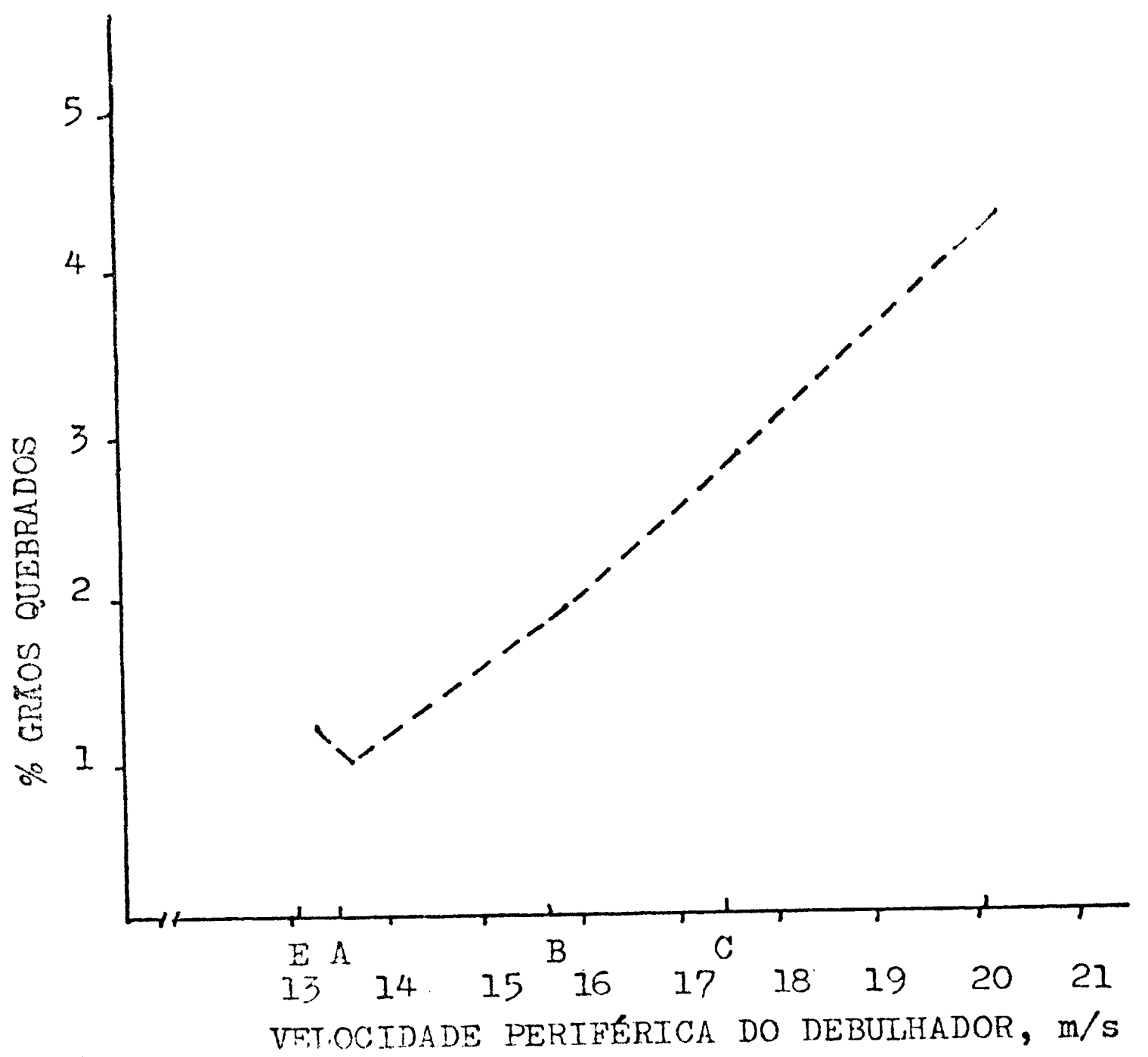

FIGURAS 2 - Relação entre a velocidade periférica do debulhador e grãos quebrados 
Esses resultados estão em concordância com os obtidos por GOSS et al (1955), MORRISON (1955) e BYG e HALL (1968).

Deve-se destacar que a porcentagem de grãos inteiros obtidos no ensacador representa em última análise, a eficácia do sistema debulhador e de limpeza.

Procurou-se avaliar ainda o efeito da velocidade periférica do debulhador sobre a porcentagem de germinação. Esta de certa forma, caracteriza um dano invisível, apontado por JOHNSON et al (1963), como importante e geralmente com conseqüências futuras.

Os dados obtidos apresentaram a análise de variância mostrada no Quadro 6, apresentado abaixo.

Quadro 6 - Análise de variância referente a porcentagem de germinação.

\begin{tabular}{lcrcr}
\hline $\begin{array}{l}\text { Causas de } \\
\text { variação }\end{array}$ & G L & $\begin{array}{c}\text { Soma dos } \\
\text { quadrados }\end{array}$ & $\begin{array}{c}\text { Quadrados } \\
\text { médios }\end{array}$ & F \\
\hline Blocos & 5 & $2.147,5800$ & 429,5200 & $8,49^{* *}$ \\
Tratamentos & 4 & 691,5900 & 172,9000 & $3,42^{* *}$ \\
Resíduo & 20 & $1.012,6000$ & 50,6000 & \\
\hline Total & 29 & $3.851,7700$ & & \\
\hline
\end{tabular}

$\mathrm{CV}=11,28 \%$

Nos testes das médias o tratamento A diferiu significativamente Ge todos os outros tratamentos com exceção do tratamento B. Este diferiu significativamente nos restantes, com exceção do tratamento A. O tratamento $\mathrm{C}$ diferiu significativamente de todos os tratamentos com exceção do tratamento E. Este diferiu significativamente dos outros tratamentos com exceção dos tratamentos $C$ e $D$.

Confrontando-se as colunas (1) e (6) os dados sugerem uma relação inversa entre a velocidade periférica do debulhador e a porcentagem de germinação dos grãos inteiros de milho. Nos tratamentos A e E onde os valores da velocidade periférica não diferiram, poder-se-ia esperar que os resultados da porcentagem de germinação não diferissem também; o que não ocorreu. Tal fato de certa forma pode ser explicado se atentar-se para o Quadro 2 parte I, onde para o tratamento E, a velocidade de deslocamento da colhedora foi o dobro daquela para o tratamento A, implicando em um fluxo de espigas comparativamente mais elevado. Estudos mais aprofundados a esse respeito se fazem necessários, considerando-se a perspectiva de aplicação desta máquina para a colheita de sementes de milho. 


\section{CONCLUSÕES}

A análise e discussão dos resultados obtidos conduzem às seguintes conclusões:

As porcentagens de grãos inteiros obtidos no ensacador, sugerem uma relação inversa com respeito às velocidades perfféricas do debulhador, nas condições do ensaio. A velocidade periférica do debulhador varia em média de $13,31 \mathrm{~m} / \mathrm{s}$ a $20,16 \mathrm{~m} / \mathrm{s}$ enquanto que as porcentagens médias de grãos inteiros decrescem de $96,98 \%$ para $82,06 \%$.

Com referência à porcentagem de grãos quebrados obtidos no ensacador e a velocidade periférica do debulhador houve uma relação direta entre as cuas variáveis, nas condições do ensaio. As porcentagens médias de grãos quebrados, apresentaram valores crescentes de $0,94 \%$ a $4,31 \%$.

A avaliação dos danos mecânicos invisíveis provocados pela velocidade periférica do debulhador, através de teste de germinação, mostrou uma relação inversa entre a velocidade periférica do debulhador e a sistema debulhador, cujos valores decresceram de $84 \%$ a $72 \%$, estudos mais aprofundados a esse respeito são necessários para se obter relações consistentes entre as diversas variáveis envolvidas.

\section{SUMMARY}

\section{"PERFORMANCE OF THE PENHA CLM-350 CORN HARVESTER - PART III - "MECHANICAL DAMAGE"}

This work deals with the effect of the shelling system of a corn harvester on the quality of corn kernels. The mechanical damage, both visible and invisible were evaluated, the last one using germination tests. The moisture content of the kernels for each treatment was determined.

The periphral velocity of the shelling cylinder was defined considering the diameter $(300 \mathrm{~mm})$ and the angular velocity for the various treatments.

The statistical design used was randomized blocks with 5 treatments and 6 repetitions to study the percentage values of whole and broken kernels, the correspondent moisture content and germination values. The $F$ test at $1 \%$ and $5 \%$ probability level and Tukey's test were used for comparison between means.

From the analysis it is possible to conclude that the effect of moisture content was not statistically significant with an average moisture content of $15,78 \%$.

The comparions betwcen means showed that there are highly significant differences for the peripheral velocity of the shelling cylinder on the percentage of whole kernels, 
it could be assumed that there was an inverse relation between those two parameters for the conditions tested.

The germination test which was used to characterize invisible damage showed significant differences for some of the treatments. The results indicated an inverse relation between peripheral velocity of the shelling cylinder and the percentage of germination of the whole kernels. Some influence of the material flow through the shelling system was detected suggesting further studies of this phenomenon if these harvesters are to be used to harvest corn seed.

\section{LITERATURA CITADA}

BRASS, R.W. and S.J. Marley, Roller sheller: low damage corn shelling cylinder. Transactions of the A.S.A.E St. Joseph, Michigan, U.S.A. 16(1):64-66, 1973.

$B Y G, D . M$. and G.E. Hall, Corn losses and kernel damage in field shelling of corn. Transactions of the A.S.A.E. St. Joseph, Michigan U.S.A. 11(2): 164-166, 1968.

GOSS, J.R., R. Bainer and R.G. Curley, Field tests of combines in corn. Agricultural Engineering. St. Joseph, Michigan, U.S.A. 30(12): 794-796, 1955.

JOHNSON, W.H., B.J. Lamp., J.E. Henry and G.E. Hall, Corn harvesting performance at various dates Transactions of the A.S.A.E. St. Joseph, Michigan, U.S.A. 6(3): 268-272, 1963.

MORRISON, C.S., Attachments for combining corn. Agricultural Engineering St. Joseph, Michigan, U.S.A. 36(12): 796-798, 1955.

PICKARD, G.E., Laboratory studies of corn combining. Agricultural Engineering. St. Joseph, Michigan, U.S.A. 36(12): 792-794, 1955.

WAELTY, H. and W.F. Buchele, Factors affecting corn kernel damage in combine. Transaction of the A.S.A.E. Joseph, Michigan, U.S.A. 12(1):55-59, 1969. 
